\title{
Differential Effects of Dexamethasone and Itraconazole on Aspergillus fumigatus-Exacerbated Allergic Airway Inflammation in a Murine Model of Mite-Sensitized Asthma
}

\author{
Hiroto Matsuse Chizu Fukushima Susumu Fukahori Tomoko Tsuchida \\ Tetsuya Kawano Tomoya Nishino Shigeru Kohno \\ Second Department of Internal Medicine, Nagasaki University School of Medicine, Nagasaki, Japan
}

\section{Key Words}

Aspergillus fumigates · Bronchial asthma · Dermatophagoides farinae - Allergic bronchopulmonary aspergillosis .

Itraconazole $\cdot$ Phagocytosis

\begin{abstract}
Background: Fungal exposure is associated with particularly severe asthma. Nevertheless, the effects of anti-fungal treatments on fungus-exacerbated asthma need to be determined. Objectives: The present study aimed to compare the effects of itraconazole (ITCZ) and dexamethasone (Dex) on Aspergillus fumigatus ( $A f$ )-exacerbated preexisting Dermatophagoides farinae (Df) allergen-sensitized allergic airway inflammation. Methods: Four groups of BALB/c mice were prepared: control, $D f$-sensitized plus $A f$-infected mice (Df-Af), and Df-Af mice treated with Dex (Df-Af-Dex) or with ITCZ (DfAf-ITCZ). Pulmonary pathology and cytokine profiles in the airway were evaluated. In a different set of experiments, the effects of Dex on alveolar macrophage (AM) phagocytosis of Af conidia were determined in Df-sensitized mice. Results: Af infection significantly increased the level of eosinophils and neutrophils in the airway of $D f$-sensitized mice. While Dex significantly decreased eosinophils, ITCZ significantly decreased both eosinophils and neutrophils in Df-Af mice. Dex significantly decreased IL-5, whereas ITCZ significantly re-
\end{abstract}

duced MIP-2 in the airway. Compared to controls, AM isolated from $D f$-sensitized mice had significantly reduced phagocytotic activity of Af conidia. However, Dex significantly improved phagocytotic activity of AM in Df-sensitized mice. Conclusions: The present study showed that Dex and ITCZ differently regulated $A f$-exacerbated allergic airway inflammation; the former inhibits eosinophilic inflammation and the latter inhibits neutrophilic as well as eosinophilic inflammation by regulating different cytokines. Additionally, Dex enhanced the phagocytotic activity of AM in allergic asthma. Thus, a combination of Dex and ITCZ might be effective for the management of fungus-exacerbated asthma.

Copyright $\odot 2013$ S. Karger AG, Basel

\section{Introduction}

Bronchial asthma is a representative airway inflammatory disorder that develops from the central to small airways, and involves various inflammatory cells and mediators in its pathogenesis $[1,2]$. Since human airways are directly connected to the atmosphere, numerous airborne factors are continuously reaching the airway during breathing. As a result, some of these airborne factors can potentially cause allergic airway inflammation, leading to an acute exacerbation of asthma.

\section{KARGER}

E-Mail karger@karger.com

www.karger.com/res
(C) 2013 S. Karger AG, Basel

$0025-7931 / 13 / 0855-0429 \$ 38.00 / 0$
Hiroto Matsuse, MD, PhD

Second Department of Internal Medicine

Nagasaki University School of Medicine, 1-7-1 Sakamoto

Nagasaki 852-8501 (Japan)

E-Mail hmatsuse@nagasaki-u.ac.jp 
Fig. 1. Animal preparation and drug treatment protocol scheme. BALB/c mice were each immunized intraperitoneally on days 1 and 14 with $0.5 \mathrm{mg}$ of $D f$ precipitated in aluminum hydroxide. Control group: mice were sham-sensitized i.n. with PBS on days 14, 16 and 18 and sham-infected i.n. with culture media on days 19, 21 and 23. Df-Af group: after immunization with $D f$, mice were challenged i.n. with $D f$ allergen on days 14,16 and 18 . Subsequently, mice were infected i.n. with $A f$ on days 19, 21 and 23. Df-Af-Dex group: Df-Af mice were injected s.c. with Dex on days 19, 21 and 23. Df-Af-ITCZ group: Df-Af mice were orally (p.o.) administered itraconazole on days 19, 21 and 23. On day 25, all mice were sacrificed.

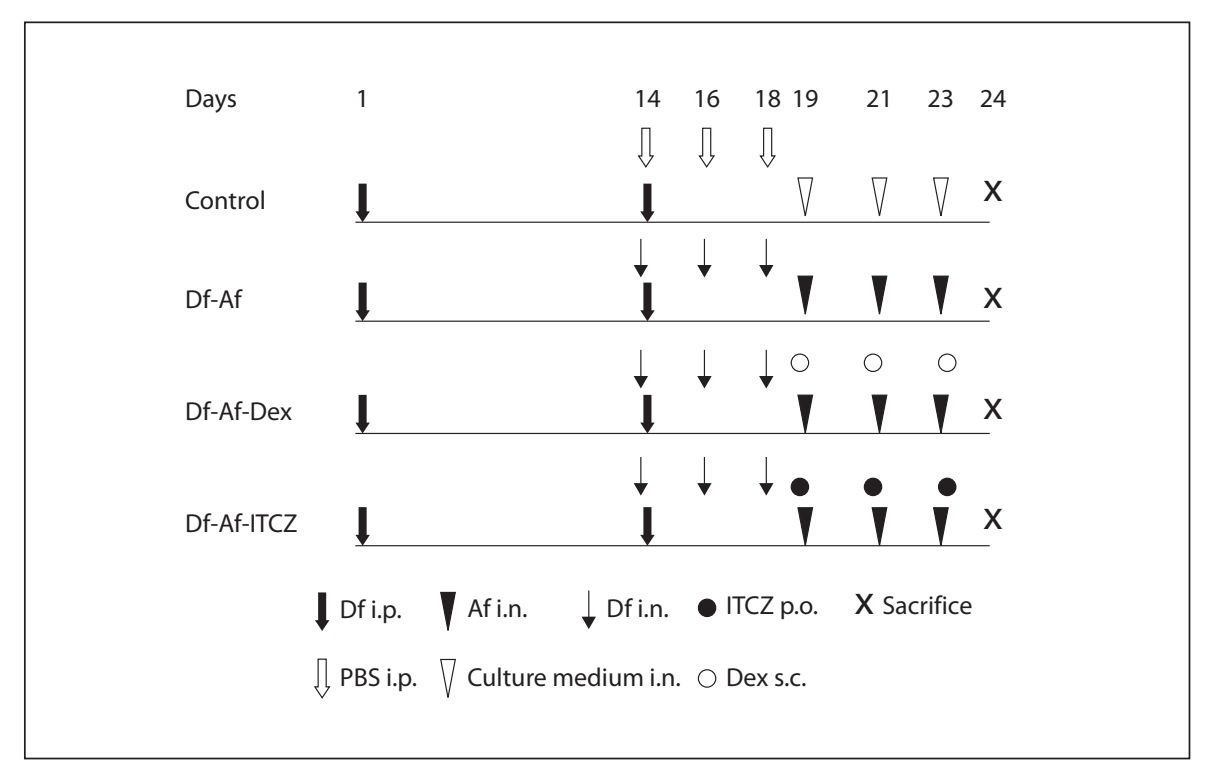

Respiratory infections are the most frequent cause of asthma exacerbation in both children and adults $[3,4]$. Indeed, respiratory viruses have been studied exclusively for their role in the worsening of asthma symptoms [5]. Aside from viruses, the link between fungi and asthma has been long established. There is sufficient evidence to indicate that exposure to outdoor and indoor fungi are associated with the severity of asthma [6-8]. Aspergillus spp. are ubiquitous within the indoor and outdoor environment, and airways colonization by Aspergillus fumigatus $(A f)$ has been demonstrated in asthmatic subjects. Allergic bronchopulmonary aspergillosis (ABPA) is a specific disease entity characterized by a highly exaggerated allergic response due to long-term colonization of the respiratory tract by $A f$ [9]. More recently, the phrase 'severe asthma with fungal sensitization', or SAFS, has been coined to define a particular phenotype of severe asthma, which is distinguished from ABPA [10]. In marked contrast to anti-virals, anti-fungal treatments are available and have the potential to be clinically useful in the treatment of fungus-exacerbated asthma. For instance, the benefit of oral itraconazole (ITCZ) has been shown in double-blind, placebo-controlled trials in patients with ABPA [11, 12]. Additionally, oral ITCZ has been reported to be effective for treating SAFS $[13,14]$.

The mouse is an excellent animal model for studying interactions between fungal infection and mite allergen sensitization. Previous reports used a model that was first sensitized to and then challenged with $A f$ protein $[15,16]$. However, since people are continuously inhaling aeroal- lergens from the atmosphere they are generally sensitized with multiple allergens. Thus, atopic subjects are likely to be initially sensitized to aeroallergens, such as mites, in utero or in early life, establishing allergic airway inflammation, and are then subsequently exposed to other allergens, such as $A f$. Based on this understanding, we previously developed a murine model of $A f$-exacerbated mite allergen-sensitized asthma [17]. Utilizing this model, the present study aimed to compare the effects of ITCZ versus corticosteroids on $A f$-enhanced preexisting allergic airway inflammation.

\section{Materials and Methods}

Preparation of Af Conidia

Af MF-13 [17] was isolated from the sputum of a patient with pulmonary aspergilloma and was subcultured on Sabouraud dextrose agar (Becton Dickinson, Cockeysville, Md., USA) at $30^{\circ} \mathrm{C}$ for 7 days. The conidia were harvested with sterile saline containing $0.02 \%$ Tween 80 (Wako Pure Chemical Industries, Tokyo, Japan), then counted in a hemocytometer and diluted with sterile saline for intranasal infection [17].

Mice

As illustrated in figure 1, four groups of mice were prepared. Four-week-old female BALB/c mice (Charles River Japan Inc., Yokohama, Japan) were immunized intraperitoneally (i.p.) on both days 1 and 14 with $0.5 \mathrm{mg}$ of Dermatophagoides farinae ( $D f$; crude extract of the mite: LG-5339; Cosmo Bio, Tokyo, Japan) precipitated in aluminum hydroxide. These mice were then challenged intranasally (i.n.) with $50 \mu \mathrm{g} / 50 \mu \mathrm{l} D$ f allergen (crude extract of the mite) on days 14,16 and 18 . Following $D f$ sensitization, control 
Fig. 2. Phagocytosis protocol scheme. BALB/c mice were each immunized i.p. on days 1 and 14 with $0.5 \mathrm{mg}$ of $D f$ precipitated in aluminum hydroxide. Control group: mice were sham-sensitized i.n. with PBS on days 14, 16 and 18. Df group: after immunization with $D f$, mice were challenged i.n. with $D f$ allergen on days 14, 16 and 18. Dex group: control mice were injected s.c. with daily doses of dexamethasone on days 15-19. Df-Dex group: Df mice were injected s.c. with daily doses of dexamethasone on days 15-19. On day 20, all mice were sacrificed.

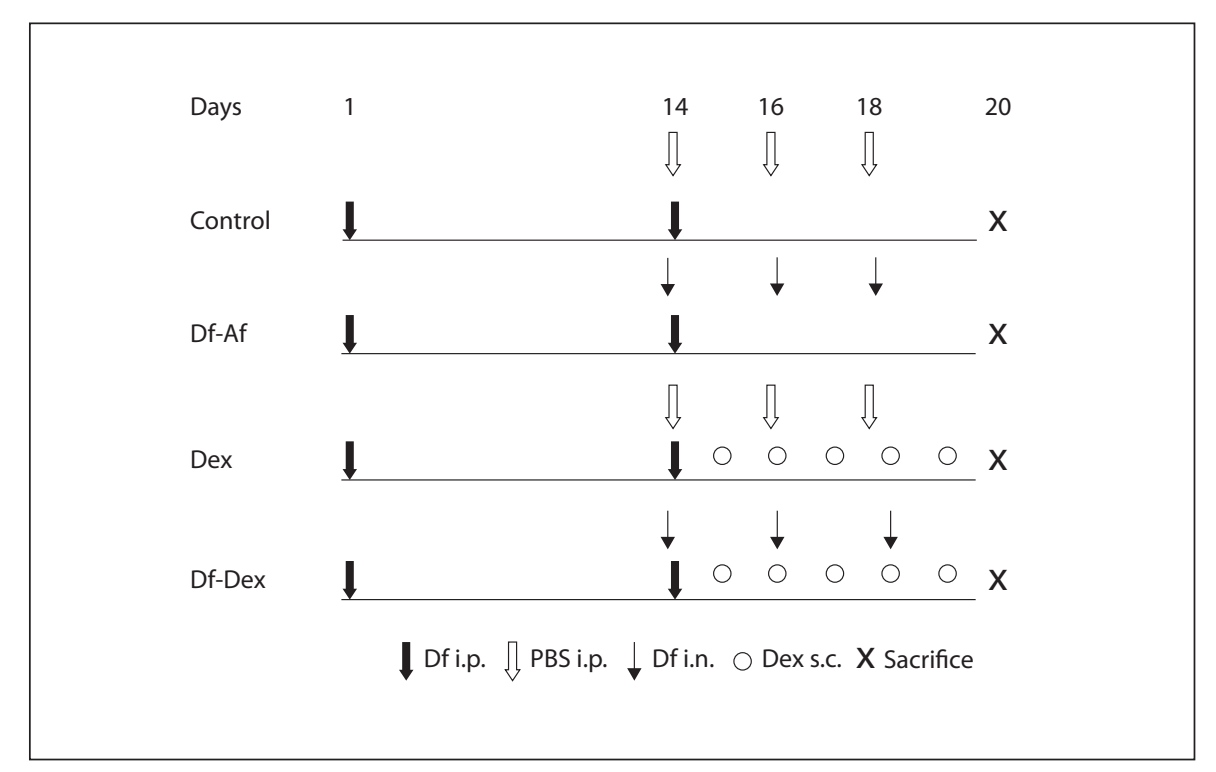

groups were challenged with PBS and subsequently sham-infected i.n. with culture media. Mice in the Df-Af group were administered $5 \times 10^{6} A f$-conidia i.n. on days 19,21 and 23 following $D f$ sensitization and the $D f$ challenge. Mice in the Df-Af group were either injected subcutaneously (s.c.) with $0.02 \mathrm{mg}$ of dexamethasone (Dex; Sigma, St Louis, Mo., USA) or orally administered 0.1 mg of ITCZ (Janssen Pharmaceutical K.K., Tokyo, Japan) on days 19,21 and 23. On day 24, all mice were sacrificed. Bronchoalveolar lavage (BAL) samples and lung tissues were obtained from each group. All procedures were reviewed and approved by the Nagasaki University School of Medicine Committee on Animal Research. In every experiment, each group consisted of 2-3 mice and all experiments were repeated three times. Finally, the findings from the three independent experiments were combined and each group consisted of 8 mice.

\section{BAL and Lung Pathology}

Twenty-four hours after final $A f$ conidia or sham infection, mice were sacrificed. BAL was conducted in the immediate postmortem period with $1 \mathrm{ml}$ of PBS, and the obtained BAL sample was centrifuged. Differential cell counts were performed using the cytocentrifuged BAL sample stained with May-GrünwaldGiemsa. Concentrations of Th2 cytokine (IL-5 and IL-13), MIP-2 (murine cytokine corresponding to human IL-8), and IFN- $\gamma$ (Th1 cytokine), in the supernatants of the BAL sample were measured by enzyme-linked immunosorbent assay, according to the manufacturer's directions (Endogen, Wobum, Mass., USA). The detection limits for IL-5, IL-13, MIP-2 and IFN- $\gamma$ were 5, 1.5, 1.5 and 10 $\mathrm{pg} / \mathrm{ml}$, respectively. Formaldehyde fixative was gently infused through the lavage catheter set in the trachea. Resected lungs were fixed for an additional $24 \mathrm{~h}$ and embedded in paraffin. Sections $(4 \mu \mathrm{m})$ were stained with hematoxylin eosin (HE), and with periodic acid-Schiff (PAS). Gomori methenamine-silver staining was also performed in order to identify $A f$ in the lung tissues and to confirm the presence of fungal spores in Df-Af mice (data not shown).

ITCZ for Af-Exacerbated Asthma

\section{Phagocytic Function of Alveolar Macrophages}

In a different set of experiments, another four groups of $\mathrm{BALB} / \mathrm{c}$ mice were prepared (fig. 2). Control and Df mice were prepared as described above. Dex and Df-Dex mice, which were also prepared as control and Df mice, respectively, were injected s.c. with a daily dose of $0.02 \mathrm{mg}$ of Dex on days $15-19$. On day 20, lung tissues were harvested from all groups of mice, then chopped with sterile scissors, digested for $2 \mathrm{~h}$ in a $37^{\circ} \mathrm{C}$ water bath containing $1.5 \mathrm{mg} / \mathrm{ml}$ collagenase A (type 1A; Boehringer Mannheim, Mannheim, Germany), and finally filtered with a metal mesh. After three washes with a RPMI-1640 medium (Gibco-BRL Life Technology Inc., Grand Island, N.Y., USA) containing 10\% heatinactivated fetal bovine serum (FBS), $100 \mathrm{U} / \mathrm{ml}$ penicillin, and 100 $\mu \mathrm{g} / \mathrm{ml}$ streptomycin (hereafter referred to as cRPMI), cells were resuspended in cRPMI. Mononuclear cells were isolated using a density gradient method with Ficoll (Amersham Pharmacia Biotech). FBS was put into a dish and incubated at $37^{\circ} \mathrm{C}$ for $15 \mathrm{~min}$. After the FBS was discarded, suspended cells were placed in the dish and incubated overnight at $37^{\circ} \mathrm{C}$. Thereafter, cells in the dish were collected using PBS containing EDTA. Aliquots $(1 \mathrm{ml})$ of cell suspension $\left(10^{6}\right.$ cells $\left./ \mathrm{ml}\right)$ were mixed with $1 \mathrm{ml}$ of $A f$ suspension $\left(10^{6}\right.$ cells $\left./ \mathrm{ml}\right)$ opsonized with $100 \mu \mathrm{l}$ of normal serum, and subsequently incubated for $60 \mathrm{~min}$ at $33^{\circ} \mathrm{C}$. Ten minutes before the completion of incubation, methylene blue $(0.01 \%)$ was added. Three areas were randomly selected per well in a blinded fashion. In each area, the number of phagocytosed conidia in two hundred conidia was counted. Results were expressed as an index representing the percentage of phagocytosed $A f$ conidia (phagocytosed conidia/600 conidia).

\section{Statistical Analysis}

Results are expressed as mean \pm standard error of the mean (SEM). Differences between groups were examined for statistical significance using repeated measures analysis of variance (ANOVA) followed by a Bonferroni correction. A p value $<0.05$ was considered statistically significant. 
Fig. 3. Pulmonary pathologies. Lung tissues were obtained from each group and stained with HE and PAS. Representative $\mathrm{HE}(\mathbf{a}, \mathbf{c}, \mathbf{e}, \mathbf{g})$ and PAS (b, d, f, h) stained photomicrographs from each group (total $\mathrm{n}=8$ for each group from three independent experiments) are shown. insets Higher magnification of inflammatory cells. Control (a, b), Df-Af (c, d), Df-Af-Dex (e, f), Df-Af-ITCZ (g, h). Scale bars $=200 \mu \mathrm{m}$.
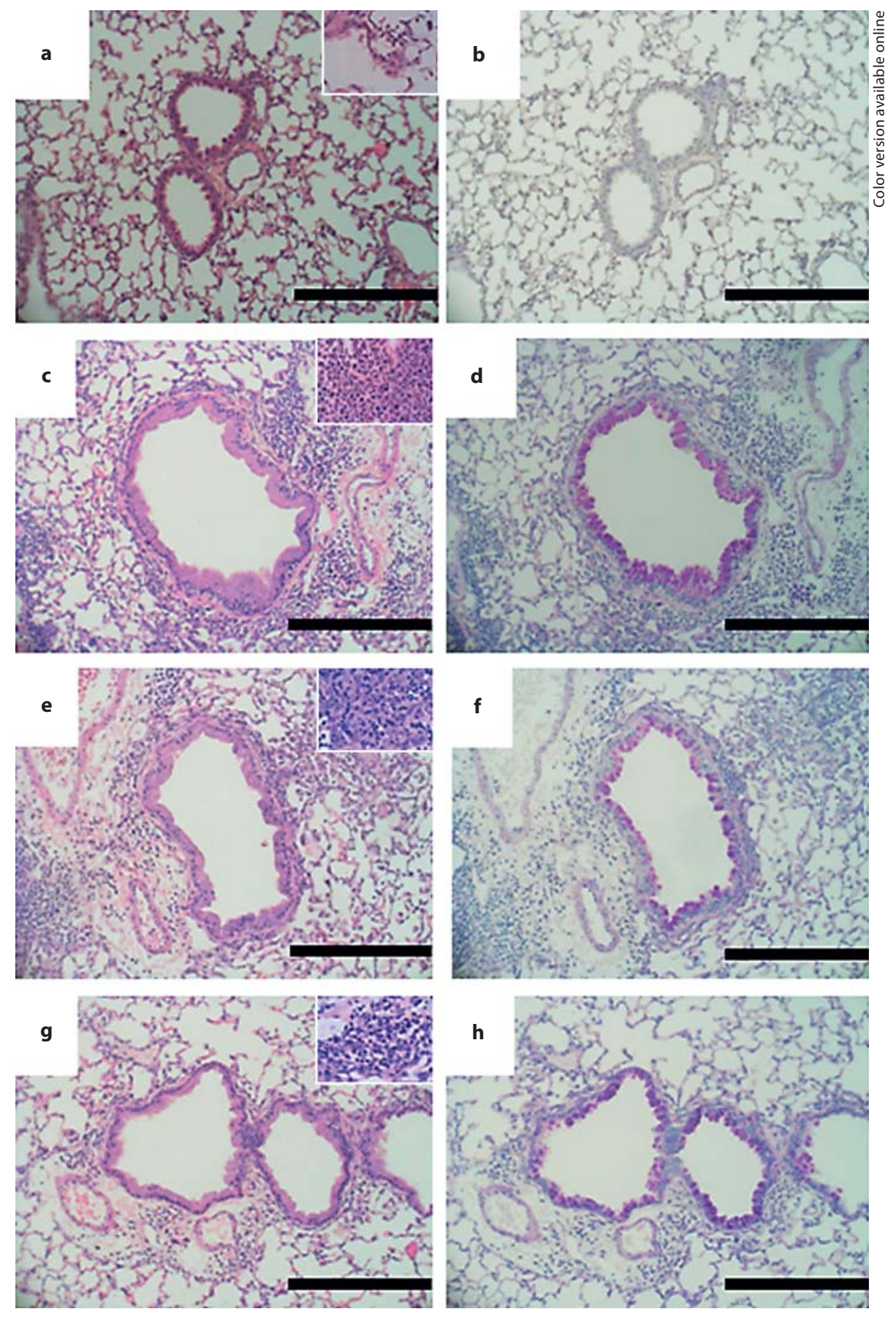

\section{Results}

\section{Pulmonary Inflammation}

Figure 3 shows some examples of pulmonary pathology observed in the study. The results of quantitative analysis of airway inflammation by BAL are shown in table 1. By comparison to control mice, Df-Af mice exhib- ited significantly increased levels of all cellular components, especially eosinophils and neutrophils. Among DfAf mice, Dex significantly decreased the level of macrophages and eosinophils, but not neutrophils. However, ITCZ was found to significantly decrease the levels of macrophages and eosinophils, as well as neutrophils in Df-Af mice. As illustrated in figure 3, neither Dex nor 
Table 1. Differential cell counts in the BAL of different groups of mice

\begin{tabular}{lccll}
\hline & Macrophages $\left(\times 10^{5}\right.$ cells $)$ & Neutrophils $\left(\times 10^{5}\right.$ cells $)$ & Lymphocytes $\left(\times 10^{5}\right.$ cells $)$ & Eosinophils $\left(\times 10^{5}\right.$ cells $)$ \\
\hline Control & $6.4 \pm 2.3$ & $0.4 \pm 1.9$ & $0.1 \pm 0.2$ & $0.0 \pm 0.0$ \\
Df-Af & $12.6 \pm 4.1^{*}$ & $9.8 \pm 3.2^{*}$ & $2.4 \pm 1.0^{*}$ & $6.2 \pm 1.7^{*}$ \\
Df-Af-Dex & $2.8 \pm 1.6^{*}$, & $10.4 \pm 6.8^{*}$ & $1.7 \pm 0.9^{*}$ & $1.1 \pm 0.2^{*} \dagger$ \\
Df-Af-ITCZ & $2.2 \pm 0.9^{*} \dagger$ & $1.8 \pm 0.5^{\dagger}$ & $1.4 \pm 0.6^{*}$ & $1.5 \pm 0.4^{*, \dagger}$ \\
\hline
\end{tabular}

BAL was performed in four groups of mice (Control, Df-Af, Df-Af-Dex, Df-Af-ITCZ). In each experiment, each group of mice consisted of 2-3 mice, and the experiment was repeated three times. Results from three independent experiments (total $\mathrm{n}=8$ for each group) were combined and expressed as means \pm SEM.

${ }^{*} \mathrm{p}<0.01$ vs. control, ${ }^{\dagger} \mathrm{p}<0.01$ vs. Df-Af.

Table 2. Cytokine concentrations (pg/ml) in the BAL of different groups of mice

\begin{tabular}{lcccc}
\hline & IL-5 & IL-13 & MIP-2 & IFN- $\gamma$ \\
\hline Control & $0.3 \pm 0.0$ & $0.2 \pm 0.2$ & $0.1 \pm 0.2$ & $67.2 \pm 5.0$ \\
Df-Af & $155.9 \pm 43.5^{*}$ & $506.8 \pm 151.0^{*}$ & $526.5 \pm 135.2^{*}$ & $2,404.2 \pm 868.4^{*}$ \\
Df-Af-Dex & $75.9 \pm 23.7^{*, \dagger}$ & $468.4 \pm 98.6^{*}$ & $600.4 \pm 178.6^{*}$ & $1,468.4 \pm 102.4^{*}$ \\
Df-Af-ITCZ & $178.9 \pm 51.8^{*}$ & $466.1 \pm 79.4^{*}$ & $112.4 \pm 16.8^{*} \dagger$ & $2,023.1 \pm 345.8^{*}$ \\
\hline
\end{tabular}

Results are expressed as means (total $\mathrm{n}=8$ for each group from three independent experiments) \pm SEM.

${ }^{*} \mathrm{p}<0.01$ vs. control, ${ }^{\dagger} \mathrm{p}<0.01$ vs. Df-Af.

ITCZ significantly reduced goblet cell hyperplasia in DfAf mice, as determined by PAS staining.

\section{Cytokine Profile in $B A L$}

Analysis of cytokine concentrations in BAL revealed that pulmonary concentrations of Th2 cytokines (IL-5 and IL-13), MIP-2 (murine cytokine corresponding to human IL-8) and IFN- $\gamma$ were significantly elevated in DfAf mice by comparison to control mice (table 2). In Df-Af mice, Dex significantly decreased IL-5, while ITCZ significantly decreased MIP-2. However, neither Dex nor ITCZ significantly affected pulmonary IL-13 and IFN- $\gamma$ concentration.

\section{Phagocytosis}

To determine the effects of in vivo Dex treatment on anti-fungal innate immunity in allergic asthma, phagocytosis of live $A f$ conidia by alveolar macrophages (AM) was compared between control, Df, Dex and Df-Dex mice. By comparison to AM isolated from control mice, AM isolated from Df mice revealed a significant decrease in phagocytosis (fig. 4). This observation suggested that preexisting allergic airway inflammation attenuates the phagocytotic activity of AM. Although Dex also significantly reduced phagocytotic activity in naïve mice, it was found to reverse phagocytotic activity against $A f$ conidia in the AM of Df mice. In our preliminary experiments, phagocytosis of live Af conidia by AM was comparable between control and ITCZ mice, indicating that ITCZ does not have a significant effect on AM (data not shown).

\section{Discussion}

In agreement with our previous report [17], we found that Afinfection enhanced both eosinophilic and neutrophilic airway inflammation, along with mucous hyperproduction in mite allergen-sensitized mice. Additionally, the current study reported that Dex and ITCZ differently regulated inflammation and the cytokine profile in the airway. Finally, while phagocytotic activity against Af was reduced in the asthmatic airway, in vivo Dex treatment prior to $A f$ infection was able to reverse this effect.

A key characteristic of fungal-associated asthma is the increased severity of the asthma. A number of studies reported that fungal-sensitized asthma has been associated 


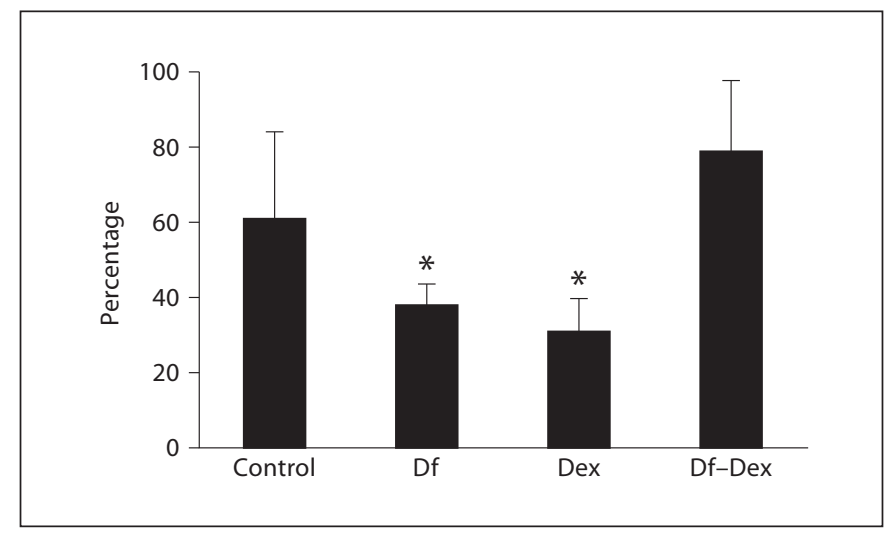

Fig. 4. AM phagocytotic activity against $A f$ conidia. AM isolated from four groups of mice were cultured with Af conidia. The number of phagocytosed conidia in each mouse was counted. Results are expressed as an index representing the percentage of phagocytosed $A f$ conidia. Bars represent mean values ( $\mathrm{n}=8$ for each group from three independent experiments) \pm SEM. ${ }^{*} \mathrm{p}<$ 0.01 vs. control.

with a risk of death, and admission to the hospital and intensive care unit [6-8]. Why fungal allergens, in particular, are implicated in such severe cases of asthma remains unclear. One key difference between fungal allergens versus other aeroallergens is that house dust mite or grass pollen is only a source of an allergenic protein, while fungi also have the capability to actively germinate and colonize the airway. Thus, fungi may have a much greater impact on patients in terms of triggering a host's defense against pathogens and producing toxins and enzymes that may play an accessory role in triggering allergy [10].

Recently, the critical role of neutrophils in the allergic airway inflammation has been reconsidered [18] and a distinct pathological feature of fungal-associated asthma is neutrophilic airway inflammation. For instance, in the present study, pulmonary pathology demonstrated significant increases in neutrophils as well as eosinophils in the airway of Af-Df mice. While ABPA is characterized by eosinophilia, it has also been correlated with increased sputum neutrophils and increased levels of IL-8 [19]. The detection of $A f$ in sputum is associated with sputum neutrophils, as well as $A f \operatorname{IgE}$ sensitization and reduced lung function [20]. The role of neutrophilic airway infiltration and MMP-9 activity in the development of airway allergy was confirmed in a murine model of fungal-sensitized asthma [21]. Neutrophilic airway inflammation caused by $A f$ may at least partially explain the increased severity of fungus associated asthma. Indeed, current anti-inflammatory therapies for asthma, including inhaled cor- ticosteroids, are effective in managing eosinophilic airway inflammation, but have little or no impact on neutrophilic airway inflammation [22, 23]. Accordingly, additive treatment, which has an impact on neutrophilic inflammation, is required for fungus-associated asthma. Due to this fact, antifungal drugs have been attracting increasing attention, and the benefits of ITCZ in ABPA have been reported in a number of studies [11, 12]. Additionally, ITCZ was reported to improve asthma-related quality of life in patients with fungal sensitization in severe asthma but free of ABPA [13]. Another retrospective cohort study also demonstrated that antifungal therapy with oral ITCZ or voriconazole significantly reduced serum total and $A f$-specific IgE as well as blood eosinophils in patients with severe asthma with fungal sensitization and ABPA [14]. In the present study, Dex was only effective at reducing eosinophilic but not neutrophilic inflammation, while ITCZ significantly reduced neutrophilic infiltration into the airway as well as eosinophilic infiltration.

To determine the molecular actions of each drug, we compared the cytokine profile in BALF between Dexand ITCZ-treated Df-Af-mice. While Dex significantly decreased IL-5, ITCZ significantly decreased MIP-2. Thus, each drug was found to differentially regulate the Af-exacerbated allergic airway inflammation. The fact that ITCZ significantly reduced eosinophils without decreasing IL-5 suggests that it might inhibit other cytokines, such as IL-17, which is critical in both allergy and infection [24]. Both drugs did not significantly influence IL-13 or IFN- $\gamma$. Since IL-13 is associated with mucous hypersecretion, it appears that both Dex and ITCZ failed to inhibit goblet cell metaplasia.

A clinical concern with utilizing corticosteroids for fungus-exacerbated asthma is the inhibition of innate immunity. Indeed, in the present study, phagocytosis against $A f$ by AM was significantly reduced in Df mice and Dex-treated naïve mice. This finding agrees with a previous report which showed that AM function is compromised in poorly controlled asthmatics and is characterized by decreased phagocytosis [25]. AM are the main phagocytotic cells in the lungs with innate immunity against $A f$ and their phagocytotic activity can be attenuated by corticosteroids [26]. Unexpectedly, AM isolated from Dex-treated Df mice showed phagocytotic activity similar to those found in control mice. Thus, at least in terms of maintaining phagocytotic activity of AM, the inhibitory effects of corticosteroids on allergic inflammation may dominate over their suppressive effects on innate immunity. 
In conclusion, the present study observed that antifungal therapy could have a benefit in fungus-exacerbated allergic asthma, which is characterized by neutrophilic inflammation that is resistant to corticosteroids. Since both Dex and ITCZ failed to inhibit mucous hypersecretion, a macrolide, which can modulate neutrophil accumulation and activation in the airways of patients with refractory asthma [27], could be another therapeutic candidate. The combination of Dex and ITCZ for the treatment of fungus-exacerbated asthma should also be evaluated in a future study.

\section{Acknowledgement}

This study was supported by Grants-in-Aid for Scientific Research (No. 17607009 and 21590968) from the Japanese Ministry of Education, Culture, Sports, Science and Technology.

\section{Financial Disclosure and Conflicts of Interest}

None of the authors have conflicts of interest to declare in relation to this study.

\section{References}

1 Boyce JA, Bochner B, Finkelman FD, 12 Wark PA, Hensley MJ, Saltos N, Boyle MJ, Rothenberg ME: Advances in mechanisms of asthma, allergy, and immunology in 2011. J Allergy Clin Immunol 2011;129:335-341.

2 Hamid Q: Pathogenesis of small airways in asthma. Respiration 2012;84:2-11.

3 Lemanske RF Jr: Viruses and asthma: inception, exacerbation, and possible prevention. J Pediatr 2003;142:S3-S7.

4 Nicholson KG, Kent J, Ireland DC: Respiratory viruses and exacerbations of asthma in adults. Br Med J 1993;342:1494-1495.

5 Contoli M, Caramori G, Mallia P, Johnson S, Papi A: Mechanisms of respiratory virus-induced asthma exacerbations. Clin Exp Allergy 2005;35:137-145.

6 O'Driscoll BR, Powell G, Chew F, Niven RM, Miles JF, Vyas A, Denning DW: Comparison of skin prick tests with specific serum immunoglobulin $\mathrm{E}$ in the diagnosis of fungal sensitization in patients with severe asthma. Clin Exp Allergy 2009;39:1677-1683.

-7 Zureik M, Neukirch C, Leynaert B, Liard R, Bousquet J, Neukirch F, European Community Respiratory Health Survey: Sensitisation to airborne moulds and severity of asthma: cross sectional study from European Community respiratory health survey. BMJ 2002;325:411-414.

$\checkmark 8$ Agarwal R: Severe asthma with fungal sensitization. Curr Allergy Asthma Rep 2011;11: 403-413.

9 Agarwal R: Allergic bronchopulmonary aspergillosis. Chest 2009;133:805-826.

10 Denning DW, O'Driscoll BR, Hogaboam CM, Bowyer P, Niven RM: The link between fungi and severe asthma: a summary of the evidence. Eur Respir J 2006;27:615-626.

-11 Stevens DA, Schwartz HJ, Lee JY, Moskovitz BL, Jerome DC, Catanzaro A, Bamberger DM, Weinmann AJ, Tuazon CU, Judson MA, Platts-Mills TA, DeGraff AC Jr: A randomized trial of itraconazole in allergic bronchopulmonary aspergillosis. N Engl J Med 2000; 342:756-762. Toneguzzi RC, Epid GD, Simpson JL, McElduff P, Gibson PG: Anti-inflammatory effect of itraconazole in stable allergic bronchopulmonary aspergillosis: a randomized controlled trial. J Allergy Clin Immunol 2003;111:952-957.

13 Denning DW, O'Driscoll BR, Powell G, Chew F, Atherton GT, Vyas A, Miles J, Morris J, Niven RM: Randomized controlled trial of oral antifungal treatment for severe asthma with fungal sensitization: the Fungal Asthma Sensitization Trial (FAST) study. Am J Respir Crit Care Med 2009;179: 11-18.

14 Pasqualotto AC, Powell G, Niven R, Denning DW: The effects of antifungal therapy on severe asthma with fungal sensitization and allergic bronchopulmonary aspergillosis. Res-

15 Gruning G, Kurup VP: Animal models of allergic bronchopulmonary aspergillosis. Front Biosci 2003;8:157-171.

16 Hogaboam CM, Blease K, Mehrad B, Steinhauser ML, Standiford TJ, Kunkel SL, Lukacs NW: Chronic airway hyperreactivity, goblet cell hyperplasia, and peribronchial fibrosis during allergic airway disease induced by Aspergillus fumigatus. Am J Pathol 2000; 156:723-732.

17 Fukushima C, Matsuse H, Fukahori S, Tsuchida T, Kawano T, Kohno S: Aspergillus fumigatus synergistically enhances mite-induced allergic airway inflammation. Med Sci Monitor 2010;16:BR197-BR202.

18 Pelikan Z: Delayed asthmatic response to bronchial challenge with allergen-mediators, eicosanoids, eosinophil and neutrophil constituents in the blood and urine. Respiration 2011;82:225-236.

19 Gibson PG, Simpson JL, Saltos N: Heterogeneity of airway inflammation in persistent asthma: evidence of neutrophilic inflammation and increased sputum interleukin-8. Chest 2001;119:1329-1336. pirology 2009;14:1121-1127.
20 Fairs A, Agbetile J, Hargadon B, Bourne M, Monteiro WR, Brightling CE, Bradding P, Green RH, Mutalithas K, Desai D, Pavord ID, Wardlaw AJ, Pashley CH: IgE sensitization to Aspergillus fumigatus is associated with reduced lung function in asthma. Am J Respir Crit Care Med 2010;182:1362-1368.

21 Park SJ, Wiekowski MT, Lira SA, Mehrad B: Neutrophils regulate airway responses in a model of fungal allergic airways disease. J Immunol 2006;176:2538-2545.

22 Wenzel SE, Schwartz LB, Langmack EL, Halliday JL, Trudeau JB, Gibbs RL, Chu HW: Evidence that severe asthma can be divided pathologically into two inflammatory subtypes with distinct physiologic and clinical characteristics. Am J Respir Crit Care Med 1999;160:1001-1008.

23 Berry M, Morgan A, Shaw DE, Parker D, Green R, Brightling C, Bradding P, Wardlaw AJ, Pavord ID: Pathological features and inhaled corticosteroid response of eosinophilic and non-eosinophilic asthma. Thorax 2007; 62:1043-1049.

24 Cosmi L, Liotta F, Maggi E, Romagnani S, Annunziato F: Th17 cells: new players in asthma pathogenesis. Allergy 2011;66:989-998.

25 Fitzpatrick AM, Holguin F, Teague WG, Brown LA: Alveolar macrophage phagocytosis is impaired in children with poorly controlled asthma. J Allergy Clin Immunol. 2008;121:1372-1378.

26 Philippe B, Ibrahim-Granet O, Prévost MC, Gougerot-Pocidalo MA, Sanchez Perez M, Van der Meeren A, Latgé JP: Killing of Aspergillus fumigatus by alveolar macrophages is mediated by reactive oxidant intermediates. Infect Immun 2003;71:3034-3042.

27 Simpson JL, Powell H, Boyle MJ, Scott RJ, Gibson PG: Clarithromycin targets neutrophilic airway inflammation in refractory asthma. Am J Respir Crit Care Med 2008; 17: 148-155. 